\title{
Fluxos de Comércio Intra-Regionais na América do Sul: Uma Análise do Potencial Articulador do Brasil*
}

\author{
Antonio Martins Cortada**
}

Resumo: Este artigo aborda o intercâmbio comercial do Brasil na América do Sul por meio dos seus aspectos de qualidade e intensidade. Para tal fim, emprega-se uma metodologia de avaliação da competitividade do comércio, valendo-se dos conceitos de valor agregado, dinâmica e intensidade tecnológica dos produtos comercializados. Com os resultados dessa aplicação, observa-se o caráter da participação do Brasil no intercâmbio comercial do subcontinente, através de sua importância como comprador regional bem como das características dos bens transacionados. Questiona-se finalmente como incrementar a integração regional.

Palavras-chave: Integração América do Sul, Economia América do Sul, Comércio Internacional, Qualidade do Comércio, Brasil na América do Sul.

Abstract: This article approaches the Brazilian trade within South America by its aspects of quality and intensity. We apply a methodology for evaluating trade competitiveness of the South American economies, using concepts such as the aggregated value, dynamics and intensity of the traded goods. The results characterize the Brazilian participation in the sub continental trade and forwards questions on how to foster the regional integration.

Keywords: South America Integration, South America Economy, International Trade, Quality of Trade, Brazil in South America.

\footnotetext{
* O artigo baseia-se na dissertação de mestrado do autor, apresentada em abril de 2007, intitulada "Comércio e integração do Brasil na América do Sul: uma avaliação de alternativas às limitações logísticas na região amazônica”.

** Mestre em Integração da América Latina pelo Programa de Pós-Graduação em Integração da América Latina da Universidade de São Paulo - PROLAM-USP. E-mail: cortada@usp.br. Recebido em 03/06/07 e aceito em 04/12/07.
} 


\section{Introdução}

Apesar dos esforços históricos para a integração regional sul americana e da retomada do tema nas duas décadas mais recentes, o resultado geral tem sido frustrante.

Esta dificuldade para consolidar uma maior integração tanto reflete o passado colonial do continente como sua articulação ao processo de acumulação capitalista. Neste, os países da região, por mais que tenham alterado suas estruturas produtivas e se desenvolvido, continuam com uma inserção periférica, dependentes da dinâmica de acumulação engendrada a partir das economias centrais.

Essa subordinação dinâmica e dependência restringem as possibilidades de integração intra-regional em todos os prismas, pois os vínculos econômicos dos países da América do Sul são mais estreitos com as economias centrais que entre si.

Apesar das frustraçóes nos esforços de integração, esta permanece no anseio dos povos da regiáo. Por argumentos racionais ou emocionais, pela racionalidade econômica ou pela geografia, parece haver uma percepçáo da inevitabilidade de uma identidade latino-americana, seja construída na própria região ou reflexo do olhar externo. Como derivada, há uma percepção da inequívoca necessidade (ainda que não da factibilidade) da integração regional.

Muito embora o comércio não seja a única motivação, são os ganhos de bem-estar que ele proporciona a base para que qualquer processo de integração possa avançar e consolidar-se (KRUGMAN, OBSTFELD, 2005). Esta permanente contraposição "necessidade versus factibilidade" da integração intra-regional ganha importância ante a percepção da urgência que o momento histórico impóe com a sua dinâmica de globalização. A maior inserção das economias da regiấo, de maneira mais articulada, nos fluxos globais de comércio, tenderia a resultar em maiores benefícios para sua população.

No entanto, o ritmo da globalização é muito rápido e as economias regionais têm sido pressionadas a uma inserção individual e desarticulada.

Entre os aspectos menos explorados quanto à integração econômica intra-regional encontra-se o estudo das características dos fluxos de comércio 
entre os próprios países da região, mais especificamente da América do Sul: quem comercializa o quê, com quem e como se operam fisicamente os fluxos comerciais.

Uma das questóes subjacentes a este artigo é se o comércio intraregional representaria atratividade suficiente para permitir que as economias latino-americanas se articulassem e agissem de forma conjunta, ainda a tempo de se beneficiar deste momento da história, de aprofundamento da internacionalização do capital.

Neste ambiente, qual efetivamente é a importância do Brasil no comércio intra-regional? O Brasil teria como constituir-se no elemento articulador do processo de integração regional, no atual momento histórico?

O presente artigo busca colaborar para as questóes apontadas, ressaltando alguns aspectos da prática do relacionamento comercial entre os países da América do Sul. Em particular, busca-se entender o papel que o Brasil tem desempenhado como a economia de maior destaque do subcontinente. É evidente que a melhor compreensão de como a integraçáo tem ocorrido na prática do comércio contribuirá para que as eventuais novas tentativas de integração, bem como de incremento das relaçóes comerciais ou políticas, tenham maiores possibilidades de sucesso.

Para isto o artigo retoma, na seção seguinte, a visão centro-periferia para tratar o processo de integração, propondo o uso de uma abordagem dinâmica do comércio.

$\mathrm{Na}$ próxima seção são mostrados os referenciais analíticos que suportam nossa análise, consistindo na seleção e aplicação de modelos que estudam o comércio internacional através da dinâmica e intensidade tecnológica dos produtos comercializados. Estes referenciais são aplicados ao intercâmbio comercial do Brasil com os demais países da América do Sul.

Em seguida, avalia-se até que ponto o Brasil pode ser entendido como uma economia com potencial de constituir-se em articulador regional, através dos indicadores que mostram sua dimensão, a composição de sua produção e do seu comércio. É ressaltado o fato de como a relação comercial do Brasil com os demais países da regiáo poderia conter características de uma relação centro-periferia.

Finalmente, na última seção são apresentadas algumas reflexões, 
destacando observaçóes sobre como os atuais vínculos comerciais entre os países da regiáo podem ser explorados, em particular como superar as limitaçôes do comércio como vetor principal da integração continental.

\section{Um dilema competitivo: prioridade "extra" ou "intra" regional}

Desde os primeiros trabalhos com a chancela da CEPAL a questão da integração regional latino-americana esteve presente. No entanto, o que acabou por predominar, na prática, foi a implantação de projetos nacionais de industrialização, em detrimento dos esforços de ação regional conjunta e articulada.

$\mathrm{O}$ próprio discurso da CEPAL quanto à integração produtiva não tem sido estável, passando por diferentes ênfases, claramente associadas com as prioridades econômicas enfrentadas ao longo da história.

Braga (2002, p. 11) classifica estas alteraçóes no foco do pensamento cepalino voltado para a integração econômica regional em duas fases distintas, entremeadas por um período voltado mais ao ajuste macroeconômico que à integração. Na primeira fase a integração seria parte "de uma estratégia de desenvolvimento econômico e, em particular, do processo de substituição de importaçóes proposto pela CEPAL na década de 50" (BRAGA, 2002, p.11). $\mathrm{Na}$ segunda fase [...] "busca na integração regional uma maior inserção das economias latino-americanas na economia internacional. Trata-se do regionalismo aberto." (BRAGA, 2002, p. 11).

É possível denominar o primeiro momento como integração "para dentro", para atender o objetivo da industrialização, visto como motor do desenvolvimento. O último momento pode ser chamado de uma integração "para fora": "integrar os países" da região com o objetivo de conduzi-los à "inserção competitiva" no comércio global.

A integração para dentro - que no presente artigo também denomina de "intra-regional" -, embora não tivesse sido abandonada pelo conjunto do pensamento cepalino, ficou, até início da década de 1990, em segundo plano nas discussóes e projetos políticos nacionais. $\mathrm{O}$ tema voltou a ganhar destaque em anos mais recentes, em função dos esforços dedicados à integração para fora (neste artigo também denominada como "extra-regional") e à formação 
de blocos econômicos sub-regionais.

Isto ocorre, não só pelas oportunidades próprias que a integração regional ofereceria, como a ampliação do comércio; mas, e principalmente, pela percepção que ela poderia constituir-se em um estágio preparatório para uma integração maior da região nos fluxos globais de comércio.

Além das imposiçóes históricas, existe um claro dilema estratégico colocado às nações da América do Sul, e que se reflete na profusão de propostas de integração comercial. Este dilema é entender qual a real importância da integração intra-regional para o desenvolvimento futuro destes países. Seria a integração um benefício em si, com as suas oportunidades de comércio mútuo? Os benefícios justificariam os esforços exigidos para permitir a ampliação do comércio regional?

A integração regional será uma etapa preparatória -e necessária- para a inserção competitiva de cada economia no teatro global? Ou essa integração é prescindível, e seria preferível avançar diretamente para integraçóes comerciais e produtivas com economias e blocos econômicos já constituídos, de maior dimensão e mais dinâmicos que os potenciais arranjos regionais?

\section{A visão centro-periferia e a análise dos fluxos comerciais}

A abordagem centro-periferia adotada neste artigo é a geralmente utilizada nos estudos da CEPAL, expressa por Di Filippo (1998, p. 3):

[...] En la definición del sistema centro-periferia tal como éste se presentaba afines de los años cuarenta, el rasgo original del Estudio fue tomar como punto de partida el progreso técnico y combinar analíticamente las asimetrías sectoriales inherentes al desarrollo económico del período, con las posiciones centrales y periféricas en la economía mundial. Al aplicar las asimetrías sectoriales de aquel proceso de desarrollo al plano internacional, nace efectivamente el sistema centro-periferia en la versión examinada por el Estudio. 
Embora sempre tenha havido questionamentos quanto à validade da teoria da dependência e à visão centro-periferia, são muitos os estudos que mantêm esta abordagem. ${ }^{1}$

Apesar das mudanças no processo de acumulação do capital, das alteraçóes na estrutura das economias e da significativa alteração na composição do fluxo de comércio internacional da região, a tradicional contraposição "centroperiferia” subsiste para a compreensão do subcontinente latino americano.

No início prevaleceu uma leitura mais estática desta contraposição: produtos manufaturados versus primários, embora a própria CEPAL já contemplasse a necessidade de incorporação permanente de tecnologia. Hoje a contraposição deve ser observada de maneira dinâmica, principalmente para a análise das relações comerciais dos países nos extratos intermediários de desenvolvimento, como o Brasil.

No intercâmbio atual, ainda que permaneça um forte peso de produtos primários e semi-elaborados, os produtos manufaturados têm importante presença na pauta de exportaçóes dos países periféricos, tornando esta assimetria menos evidente.

Mas a sua dinâmica é clara: os países centrais são capazes de, continuamente, introduzir no mercado produtos com maior conteúdo tecnológico e com maior valor agregado, do que aqueles produzidos pelos países periféricos. Estes últimos, mesmo incorporando a produção de manufaturados com valor agregado crescente, tendem a fazê-lo com uma defasagem tecnológica em relação aos principais produtos dos países centrais.

\section{Modelos referenciais para a análise do comércio}

Benavente (2001, p. 9) aponta que o fator mais importante para o crescimento das exportaçóes de manufaturas dos países da América Latina tem sido o acesso aos mercados dos próprios sócios regionais de integração e este crescimento sinaliza simultaneamente a existência de alguns elementos. Em primeiro lugar, haveria uma falta de competitividade internacional das manufaturas dos países da regiáo, uma vez que o crescimento deste comércio para seus parceiros regionais é possível, principalmente, pelas vantagens

\footnotetext{
${ }^{1}$ Não retomaremos aqui a discussão da validade da Teoria da Dependência e suas variantes, para uma introdução veja Machado (1999), bem como Rollinat (2005), Di Filippo (1998) e Ocampo (2001).
} 
relativas que um parceiro obtém ao participar de um acordo de integração. Em segundo lugar, há ainda possibilidades de crescimento a serem exploradas dentro do mercado regional, para ampliação do comércio de manufaturas, mantido o mesmo padrão de proteção propiciado pela integração. Em terceiro lugar, há sinais de que o crescimento do comércio entre os países da regiāo teria caracterizado uma dicotomia na sua estrutura exportadora: aos sócios dos esquemas de integração dirigem-se principalmente produtos manufaturados, enquanto para o resto do mercado mundial exportam-se produtos básicos ou com baixo (ou menor) grau de elaboração.

Adicionalmente Benavente (2002) aponta não só que as manufaturas produzidas na região apresentam pouca penetração internacional, como elas se caracterizam por serem pouco dinâmicas. Ocampo (2001, p. 37) também afirma que os fluxos comerciais intra-regionais concentram proporcionalmente mais bens industriais e com maior conteúdo tecnológico se comparados às vendas extra-regionais. Depreende-se dos autores que o crescimento do comércio de manufaturas na região está ocorrendo sob proteção e através de produtos que são pouco dinâmicos no mercado internacional.

Alinhado com esta visão, estudo da "United Nations Conference on Trade and Development” (UNCTAD) citado por Kuwayama e Lima (2003), mostram uma direta associação entre o dinamismo exportador, o valor agregado das exportaçóes e a complexidade tecnológica dos bens exportados. Segundo Kuwayama e Lima (2003, p. 9):

[...] En los documentos de la CEPAL se ha demostrado que no basta aumentar la integración de las economías nacionales en el ámbito internacional para que se establezca un vínculo positivo entre el comercio y el crecimiento económico, sino que es necesario mejorar la calidad de esa integración (CEPAL, 2001a, 2002a). Una economía altamente dependiente de los ingresos generados por la exportación de unos pocos productos o hacia algunos mercados es más vulnerable que otra cuyas exportaciones sean más diversificadas. De la misma manera, productos con un consumo poco dinámico tampoco pueden generar un crecimiento económico sostenible. Otros criterios para medir la calidad de la inserción internacional de una economía son el contenido tecnológico o el valor agregado neto de las exportaciones, así como 
los vínculos productivos que las actividades exportadoras originan al interior de la economía, en el sector manufacturero o el primario, o en el deservicios.[...] (Grifo nosso)

Benavente (2002, p. 9), por sua vez, afirma:

[...] Dado que, como se expone en el estudio citado, la tecnología se encuentra en la base del desarrollo de una industria exportadora dinámica y competitiva, capaz de garantizar un desarrollo industrial auto sostenido, un primer aspecto que debe tenerse en cuenta se refiere a la composición tecnológica del comercio intrarregional. Para ello debe contarse con una clasificación de los productos transados basada en su contenido tecnológico.[...]

Em última instância, produtos mais dinâmicos permitirão aos países exportadores ampliar a renda, enquanto aqueles exportadores de produtos menos dinâmicos tenderão a, relativamente, perder renda com o passar do tempo. Observando o conjunto destes trabalhos, é evidente a reprodução, agora de maneira muito mais dinâmica, da assimetria centro-periferia anteriormente expressa por Di Filippo.

Com o suporte desta mesma lógica dos autores acima, a CEPAL tem regularmente aplicado a ferramenta "Competitive Analysis of Nations" $(\mathrm{CAN})^{2}$ para entendimento da competitividade dos países latino americanos. Utilizando esta metodologia para analisar o período de 1990 a 1998, Benavente (2002) classificou os produtos manufaturados em dois grupos:

- Produtos dinâmicos: aqueles cujo comércio apresenta taxa de crescimento superior à taxa de crescimento do comércio mundial de manufaturados;

- Produtos "estancados" estagnados: aqueles com taxa de crescimento inferior à taxa de crescimento do comércio mundial de produtos manufaturados. Por definição, os primeiros ganham participação no comércio internacional, enquanto os segundos perdem. Entre os dinâmicos são considerados:

- Muito dinâmicos: os produtos que aumentaram, no período estudado, sua participação percentual no comércio internacional em mais de $40 \%$ em relação aos seus percentuais do período anterior;

${ }^{2}$ Mais informações do modelo podem ser obtidas em http://www.eclac.cl/software/cepal8d.htm. 
- Dinâmicos: os produtos que aumentaram sua participação percentual no comércio internacional entre $10 \%$ e $40 \%$, em comparação com os percentuais do período anterior; e

- Pouco dinâmicos: os produtos que aumentaram sua participação percentual no comércio internacional em menos de 10\%, em comparação com os percentuais do período anterior.

Os produtos mais dinâmicos tendem a ser os de alta tecnologia, como produtos de informática, eletrônicos e medicamentos. São poucos os produtos com comércio "muito dinâmico" (ou "dinâmico") que não tenham elevado conteúdo tecnológico e, quando ocorrem, estão associados a vantagens geográficas ou comerciais específicas. (BENAVENTE, 2002, p.12)

Segundo o "Informe de Desenvolvimento Industrial 2002-2003" da "Organização das Nações Unidas para o Desenvolvimento Industrial" (ONUDI) (apud. CEPAL, 2003, p. 9), os cinco produtos de maior crescimento no comércio mundial no período 1980-1997 estavam relacionados a indústrias altamente dinâmicas, como tecnologia da informação e telecomunicaçóes. Associando o conceito de dinamicidade com o de intensidade tecnológica, Piva e Cortés (2004) realizaram uma análise da intensidade tecnológica do comércio internacional de alguns países centro-americanos, observando a competitividade de suas exportaçóes.

Para a realização dessa análise os referidos autores apresentam algumas metodologias de classificação utilizadas para medir a intensidade tecnológica do comércio internacional, em particular das exportaçóes. Os trabalhos destes autores reforçam que os países que apresentam em sua balança comercial maior presença de produtos com valor agregado mais elevado, em proporçáo a outros países, têm maior competitividade e maior capacidade de gerar e manter um fluxo de renda.

Como visto anteriormente neste artigo, resgatada a visão centroperiferia em uma maneira mais atualizada, a assimetria entre a qualidade (ou dinamismo) da composição das exportaçóes em comparação com a composição das importações é justamente um dos elementos centrais para caracterizar a relação de dependência entre países. Sendo assim, também neste nível de análise fica claro que, apesar das grandes alterações que as 
economias da América Latina sofreram desde a década de 1950, em particular com avanços significativos na industrialização, o conceito centro-periferia, utilizando com uma abordagem mais dinâmica, ainda é aplicável para a compreensão de seu posicionamento com relação ao sistema produtivo global. Como no passado, sua posição competitiva permanece desfavorável.

Por outro lado, as condições da competitividade comercial dos países da América Latina certamente não são homogêneas. Alguns países têm uma composição de suas exportaçóes mais dinâmica que outros, permitindo-lhes melhor inserção nos fluxos globais de comércio.

Segundo Di Filippo (1998, p. 10):

[...] Desde este punto de vista, los centros, fuente de la presente revolución tecnológica, siguen siendo los mismos que hegemonizaron las relaciones políticas y económicas internacionales durante este siglo: Estados Unidos, la Unión Europea (con “centro" en Alemania) y el Japón. El escenario de las periferias se ha ido diferenciando internamente con estratos "superiores" como las (hasta hace poco) exitosas economías del Asia oriental, "intermedios" como las emergentes economías latinoamericanas, e "inferiores" como las economías más castigadas del África al sur del Sahara. (grifo nosso)

Com base neste referencial, podemos observar os fluxos comerciais entre o Brasil e os demais países da América do Sul, quanto à sua composição e intensidade tecnológica, utilizando-os como parâmetros para inferir sua competitividade internacional e as relações existente entre eles.

\section{Brasil: uma centralidade fraca}

Consoante com a seção anterior, a visão centro-periferia deve ser ajustada para uma versão dinâmica da assimetria, através da qualidade - agregação de valor e dinamicidade dos produtos - do comércio exterior entre os países, como forma de sinalizar uma relação de dependência entre as economias.

Mas cabe destacar que essas assimetrias, embora predominantes nas relaçóes centro-periferia, também existem nas relaçóes entre países situados na periferia. 
Dentre estes há aqueles que logram incorporar ou gerar continuamente maiores avanços tecnológicos em sua estrutura produtiva. Enquanto outros permanecem mais fortemente dependentes de estruturas produtivas tradicionais e produtores de bens com menor conteúdo tecnológico. E o intercâmbio entre eles também pode ser desigual.

Mantida a atualidade e relevância analítica da visão centro-periferia, ela pode também auxiliar a compreensão da dinâmica das relações comerciais dentro da própria periferia. Posto de outra maneira: utilizando a visão centroperiferia, como podem ser analisadas as relaçóes comerciais entre países que se situam, no seu conjunto, em uma posição de periferia?

A economia brasileira, em particular, apresenta dimensão, complexidade e uma pauta de comércio bem mais diversificada e de melhor qualidade que seus parceiros da América do Sul.

As estatísticas da ALADI mostram que o Brasil, com um PIB de 797 bilhões de dólares representou em 2005 cerca de 30\% da renda dos países da ALADI, ou metade da renda da América do Sul. O PIB da Argentina, segundo em tamanho na América do Sul, representou menos de um quarto do brasileiro.

O único país a comparar-se em produto na região latino-americana é o México, com um PIB de US\$ 768 bilhóes em 2005. O comércio exterior do México mostrou-se muito maior que o do Brasil, com as exportaçóes totalizando US\$ 250 bilhóes. Deste total, no entanto, somente US\$ 8 bilhões dirigiram-se aos países da ALADI, dos quais o país importou US\$ 12 bilhóes.

Embora nenhum país exporte tanto para seus parceiros da ALADI como o Brasil, no que respeita às importaçóes oriundas da própria regiāo há outros três países que têm importante presença como compradores da região: Argentina, Chile, e México (Tabela 1, linhas 3 e 4).

Entre 1990 e 2006, as exportaçóes totais dos países componentes da "Associação Latino-Americana de Integração" (ALADI) cresceram quase cinco vezes, passando de 126 bilhóes de dólares para 620 bilhóes. As exportaçóes do Brasil cresceram um pouco menos, 4,4 vezes. Passaram dos US\$ 31,4 bilhões em 1990, para US\$ 137 bilhões em 2006, levando a um pequeno declínio na participação do Brasil nas exportações, de $25 \%$ para $22 \%$ do 
total. As exportaçóes intra-regionais apresentaram crescimento ainda maior. Dos US\$ 12,6 bilhões em 1990, passaram a US\$ 90 bilhóes em 2006, um crescimento de sete vezes.

Apesar do crescimento do comércio intra-regional, este é menos representativo que o extra-regional. Somente $15 \%$ das suas exportaçóes totais dos países da região, em 2006, dirigiram-se a outros parceiros regionais (ante $10 \%$ em 1990).

Neste intercâmbio intra-regional o Brasil, em 2006, exportou US\$ 31 bilhôes (FOB), importando US\$ 17 bilhóes (CIF), ou 19\% do comércio intra-regional.

Mesmo sendo o maior parceiro regional, ainda assim o Brasil tem pequena representatividade nos interesses comerciais dos países da América Latina. Boa parte do que absorve são importações dos sócios do MERCOSUL. 
Tabela 1 - Indicadores de Comércio Exterior - membros selecionados da ALADI - 2006

Exportação global FOB (US\$ mi)
Importação global CIF (US\$ mi)
Exportação intra-regional FOB (US\$ mi)
Importação intra-regional CIF (US\$ mi)
Exportação intra-regional/global (\%)
Importação intra-regional/global (\%)
Exportaçôes pelo Brasil (FOB)
Importaçóes pelo Brasil (CIF)
Saldo Brasil
\% Brasil como comprador das Export.totais
\% Brasil c/comprador das Exp.intra-regionais

$\begin{array}{cccccc}\text { ALADI } & \text { Argentina } & \text { Bolívia } & \text { Brasil } & \text { Chile } & \text { Colômbia } \\ 620281 & 46423 & 4007 & 137470 & 55884 & 24373 \\ 517741 & 34160 & 2824 & 95903 & 34833 & 26162 \\ 90.136 & 18417 & 2523 & 31384 & 8630 & 5823 \\ & 14796 & 1663 & 17175 & 12785 & 8153 \\ 15 & 40 & 63 & 23 & 15 & 24 \\ & 43 & 59 & 18 & 37 & 31 \\ 31.384 & 11.712 & 693 & & 3.894 & 2.128 \\ 17.175 & 8.480 & 1.639 & & 2.991 & 267 \\ 14.209 & 3.232 & -946 & & 903 & 1.861 \\ 3 \% & 18 \% & 41 \% & & 5 \% & 1 \% \\ 19 \% & 46 \% & 65 \% & & 35 \% & 5 \%\end{array}$

Exportação global FOB (US\$ mi)

Importação global CIF (US\$ mi)

Exportaçáo intra-regional FOB (US\$ mi)

Importação intra-regional CIF (US\$ mi)

Exportação intra-regional/global (\%)

Importação intra-regional/global (\%)

Exportaçôes pelo Brasil (FOB)

Importaçôes pelo Brasil (CIF)

Saldo Brasil

\% Brasil como comprador das Export.totais

$\%$ Brasil c/comprador das Exp.intra-regionais

\begin{tabular}{|cccccc|}
\hline Equador & México & Paraguai & Peru & Uruguai & Venezuela \\
12363 & 250397 & 1906 & 22737 & 3952 & 60769 \\
12049 & 256290 & 5898 & 15294 & 4775 & 29553 \\
2631 & 8165 & 1128 & 4118 & 1407 & 5910 \\
4560 & 12445 & 2377 & 6639 & 2929 & 10185 \\
21 & 3 & 59 & 18 & 36 & 10 \\
38 & 5 & 40 & 43 & 61 & 34 \\
871 & 4.441 & 1.230 & 1.500 & 1.004 & 3.553 \\
32 & 1.366 & 308 & 805 & 640 & 615 \\
839 & 3.075 & 922 & 695 & 364 & 2.938 \\
$0 \%$ & $1 \%$ & $16 \%$ & $4 \%$ & $16 \%$ & $1 \%$ \\
$1 \%$ & $17 \%$ & $27 \%$ & $20 \%$ & $45 \%$ & $10 \%$ \\
\hline
\end{tabular}

FONTE: Indicadores Sócio-Econômicos - ALADI e BADECEL

\section{Metodologia proposta para a análise dos vínculos comerciais do Brasil}

Realizamos a reagrupação das estatísticas de comércio exterior do Brasil com seus parceiros regionais e para isto adotamos como base a mesma tipologia ajustada e apresentada por Benavente (2001) e complementada por Kuwayama e Lima (2003), inclusive quanto aos ajustes na "Classificação Uniforme para o Comércio Internacional (CUCI)" ${ }^{3}$, no nível de três dígitos.

\footnotetext{
${ }^{3}$ Para detalhes, consultar "Cuadernos Estadísticos de la CEPAL, n. 30 - Clasificaciones Estadísticas Internacionales incorporadas en el banco de datos del comercio exterior de América Latina y el Caribe de la CEPAL". Disponível em: http://www.eclac. cl/mexico/capacidadescomerciales/SeminarioSantiago,marzo2006/Documentos/GuiaBasicadeBasesdeDatosdeComercio.pdf.
} 
Com poucas diferenças, esta definiçãao de produtos manufaturados é a utilizada por outras organizaçóes, inclusive das Naçóes Unidas, como a "United Nations Conference on Trade and Development" (UNCTAD).

Realizamos alguns ajustes com relação à tipologia apresentada por Benavente, pois os dados disponíveis na base estatística para a CUCI Revisão 1 limitam-se ao detalhamento dos Grupos de Produtos (três dígitos); não estão disponíveis as Partidas (quatro dígitos) utilizadas pelo autor citado.

Esta metodologia é compatível com a tipologia da CEPAL que considera os seguintes tipos de exportaçóes:

1. Produtos Manufaturados, agrupados em três categorias:

- Insumos básicos, que compreendem produtos da indústria siderúrgica e outros de grau similar de elaboração a partir de matérias-primas,

- Tradicionais: que incluem as indústrias que tiveram implantação e desenvolvimento no início da industrialização, como couro, têxteis e calçados,

- Produtos não tradicionais: são indústrias que surgiram em fases mais avançadas da industrialização. Incluem vários tipos de produtos, com variadas intensidades de trabalho e capital nos processos produtivos e também no seu conteúdo tecnológico.

2. Produtos básicos: compreendem os produtos sem elaboração ou, ainda, os que envolvam um primeiro e básico grau de elaboração antes do comércio. Incluem, entre outros, alimentos e bebidas como café, matérias-primas agrícolas, combustíveis e minerais não combustíveis.

3. Semi-elaborados: incluem produtos agrícolas semi-elaborados, minerais semi-elaborados (como metais e produtos químicos) e derivados do petróleo.

Benavente (2002) ajusta esta tipologia com uma subdivisão dos produtos manufaturados para explicitar sua dinamicidade. Segundo o autor, há uma razoável associação entre a agregação do produto manufaturado e a sua dinamicidade no comércio. Insumos básicos tendem a ser pouco dinâmicos; os tradicionais, entre pouco dinâmicos e dinâmicos; e os não-tradicionais, com maior freqüência, tendem a ser dinâmicos.

Kuwayama e Lima (2002), por sua vez, adotam as classificações de intensidade tecnológica alta, média e baixa, também utilizadas pela CEPAL. 
O resultado destas classificaçóes pode ser observado no Quadro 1.

Quadro 1 - Tipologias de referência

\section{CEPAL e OCDE (apresentada por Benavente)}

Básicos

Semi-Elaborados

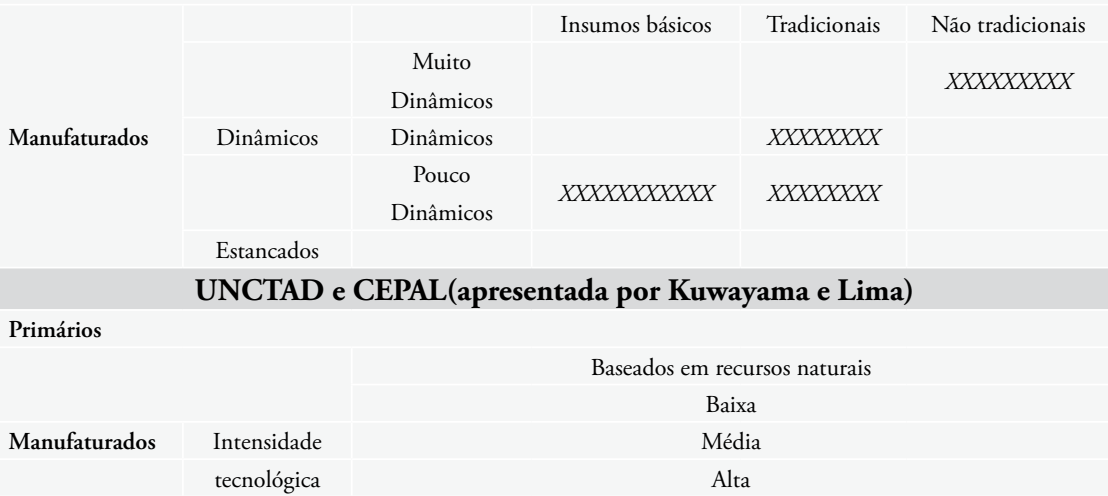

FONTE: elaboraçáo do autor com base em Benavente (2001, 2002); Kuwayama e Lima (2002)

As duas tipologias apresentadas mostram-se complementares para a observação da qualidade das relaçóes de intercâmbio entre os países da América do Sul, como proposto para este artigo. Além disso, elas são compatíveis com a disponibilidade de informações acessadas, que contêm séries históricas longas e consistentes sobre o comércio da região.

\section{Uma tipificação dos fluxos comerciais do Brasil na América do Sul}

Nossa análise focalizou os fluxos comerciais entre o Brasil e os demais países da América do Sul, reclassificando-os de acordo com a tipologia exposta.

Embora nenhum país da América Central tenha sido analisado, o México foi incluído como contraponto à posição do Brasil na região, uma vez que o país apresenta exportaçóes com as características mais dinâmicas entre os países da América Latina. Além disso, é o único país com economia de dimensão equivalente à brasileira, ainda que voltado essencialmente para o mercado norte-americano. 
A Tabela 2 condensa os dados de comércio do Brasil com países selecionados da América do Sul, classificando os saldos obtidos em cada categoria da metodologia proposta, considerando:

- O grau e o tipo de elaboração, como indicador do valor agregado,

- A intensidade tecnológica, como indicador do dinamismo das exportaçóes.

A observação conjunta dos dois aspectos sinaliza a qualidade do intercâmbio do Brasil com os respectivos parceiros ${ }^{4}$.

Há dois conjuntos claros de países. No primeiro deles, incluindo Argentina, Bolívia, Chile, Paraguai e Peru, o Brasil apresenta um balanço comercial que tende a ser pior nas categorias de menor valor agregado e menor intensidade tecnológica. Melhorando o saldo do intercâmbio à medida que a classificação melhora.

Com o segundo conjunto de países, incluindo Colômbia, Equador, México e Venezuela, o saldo é favorável ao Brasil, independente da categoria de produto.

Outro aspecto relevante é a concentração dos saldos do Brasil em produtos manufaturados não tradicionais e nos produtos de intensidade tecnológica média. Um dos grandes itens destas categorias são as vendas de máquinas, equipamentos e automóveis.

\footnotetext{
${ }^{4}$ Os dados e gráficos que suportam esta análise podem ser observados em Cortada (2007), Anexos C e D. Foi mantido o período de análise do documento original, até 2004. Os dados disponíveis até 2006 não estavam consolidados na estrutura proposta no momento do fechamento deste artigo. Os dados parciais não alteram significativamente a análise e, quando disponíveis, foram agregados aos comentários do intercâmbio de cada país.
} 
Tabela 2 - Brasil - Saldo do balanço do comércio segundo classificaçóes adotadas Milhóes de dólares - 2004

\begin{tabular}{|c|c|c|c|c|c|c|c|c|c|c|c|}
\hline \multicolumn{2}{|l|}{ Saldo } & Argentina & Bolívia & Chile & Colômbia & Equador & México & Paraguai & Peru & Uruguai & Venezuela \\
\hline \multicolumn{2}{|c|}{ Comércio Total } & 1.468 & -341 & 1.080 & 882 & 406 & 3.205 & 566 & 268 & 125 & 1.234 \\
\hline \multicolumn{12}{|l|}{ Produtos } \\
\hline \multicolumn{2}{|l|}{ Básicos } & -1.595 & -806 & 1 & 3 & -59 & 186 & -95 & -34 & -91 & 46 \\
\hline \multicolumn{2}{|l|}{$\begin{array}{l}\text { Semi- } \\
\text { elaborados }\end{array}$} & -533 & 52 & -478 & 114 & 48 & 82 & 228 & -200 & -54 & 166 \\
\hline \multirow{4}{*}{ Manufaturados } & $\begin{array}{l}\text { Insumos } \\
\text { básicos }\end{array}$ & 370 & 106 & 276 & 153 & 90 & 351 & 128 & 86 & 58 & 79 \\
\hline & Tradicionais & 353 & 59 & 157 & 94 & 30 & 150 & 67 & 49 & -26 & 66 \\
\hline & $\begin{array}{c}\text { Náo } \\
\text { tradicionais }\end{array}$ & 2.698 & 203 & 1.070 & 415 & 296 & 2.385 & 328 & 4 & 121 & 859 \\
\hline & Outros & 8 & 2 & 2 & 2 & 1 & 1 & 2 & 3 & 0 & 0 \\
\hline \multirow{3}{*}{ Intens.Tecnol. } & Baixa & -4.389 & -696 & 511 & 236 & 85 & 501 & 166 & 175 & 72 & 144 \\
\hline & Média & 255 & 146 & 798 & 250 & 234 & 2.077 & 287 & 202 & 97 & 1 \\
\hline & Alta & 705 & 39 & 195 & 113 & 41 & 171 & 58 & 65 & 32 & 159 \\
\hline
\end{tabular}

FONTE: Elaboração do autor a partir de dados obtidos no BADECEL-CEPAL

\section{Conclusões}

Observando as características do intercâmbio comercial do Brasil com os demais países da América do Sul, no que se refere ao valor total, valor agregado e à dinâmica do comércio (intensidade tecnológica) dos produtos transacionados, suas exportaçóes tendem a ter maior valor agregado, contemplam produtos com maior conteúdo tecnológico e maior dinamismo, que suas importaçóes dos respectivos parceiros.

Os resultados deste estudo, alinhados com as conclusóes de Benavente (op. cit., 2001, p. 24), indicam que o Brasil, como os demais países da América do Sul, também apresenta uma composição das exportaçóes destinadas ao intercâmbio comercial global com menor valor agregado e dinamicidade, se comparadas ao seu intercâmbio intra-regional. Nas relações comerciais com seus parceiros regionais, porém o país tem situação oposta à apresentada por ele no comércio extra-regional.

No entanto, mesmo que a maior parcela das exportaçóes intra-regionais do Brasil se concentre nas tecnologias intermediárias e não nas mais dinâmicas, elas tendem a ser mais elaboradas que as importações dos parceiros respectivos. Dessa maneira, o Brasil atua como um centro importador de produtos 
primários, semi-elaborados e elaborados tradicionais, retornando para seus parceiros, produtos manufaturados com um grau maior de agregação de valor.

Nas suas relaçóes comerciais com o Brasil, os demais países da América do Sul apresentam características similares à de periféricos. Ou, no sentido contrário, o Brasil exerce algum grau de centralidade ao constituir-se em centro comercial do subcontinente.

Como a parcela do comércio dos demais países que é absorvida pelo Brasil é pequena, esta é uma "centralidade fraca".

Mesmo com as assimetrias no comércio com seus parceiros regionais apontadas no trabalho, e ainda que seja o maior importador intra-regional, o Brasil é, em geral, um parceiro pouco expressivo dos demais países sulamericanos, absorvendo parcela muito pequena das exportaçóes destes.

Apesar de ser a maior economia da região, o Brasil não sinaliza ser atrativo o suficiente para operar como elemento promotor, ou mesmo para manter o "momentum" das iniciativas de integração já em andamento. Sua atratividade comercial mostra-se fraca adiante daquela representada pelas economias centrais: Estados Unidos, Europa e Ásia.

Entre as questôes subjacentes a este artigo, uma seria avaliar se o comércio intra-regional representaria atratividade suficiente para que estas economias atuassem de forma mais articulada no cenário da globalização. Isto para que as economias avançassem na integração ainda a tempo de participar deste momento da história, que passa pela constituição de blocos regionais. Mesmo que haja na região um reconhecimento da necessidade e das vantagens da integração intra-regional, dada a inexistência de um elemento capaz de articular os interesses no comércio intra-regional, a região tende a persistir no dilema entre priorizar a integração "extra-regional" ou a "intra-regional". Permanecerá, portanto, exposta à fragilidade que resulta da incapacidade de avançar em qualquer das opçóes de integração. $\mathrm{O}$ vetor do comércio considerado isoladamente não é, no momento, suficiente para conduzir uma integração intra-regional.

Este diagnóstico suscita um conjunto de questóes: - O processo de integração intra-regional estaria destinado a não ter continuidade? -Haveria alternativas para estimular de forma significativa o intercâmbio, mesmo na 
impossibilidade do avanço de acordos de integração?

A teoria econômica sinaliza que os movimentos de integração devam ocorrer com base no comércio e, por conseqüência, fundamentados no conjunto de instrumentos (racionais) que o configura entre os países

Por outro lado, tratar da integração entre países significa mais que comércio. Vai além da esfera econômica. As categorias "país" e "nação" são muito mais complexas, envolvendo aspectos políticos (no seu sentido mais amplo), bem como sociais e culturais.

A atratividade da integração deve ser testada também através de outras abordagens, como através da inversão da linha lógica: ela seria uma aproximação entre países, na qual o aspecto econômico é um entre os motivos.

Tratar de integração deve significar tratar três grandes vetores.

O primeiro, certamente, é o vetor econômico. Por vezes identificado como integração produtiva ou comercial. Sem dúvida é o elemento que dá consistência aos processos. O segundo é o vetor político, alinhando os interesses geoestratégicos dos países e também associando as percepçóes culturais e de identidade. Finalmente, o terceiro é o vetor físico. Que aborda a proximidade ou distância física e logística entre os países. No estágio atual da globalização, por um lado, a distância física não impede a integração comercial ou das cadeias produtivas, e pode ser compensada por uma boa logística. Por outro lado, a proximidade geográfica certamente facilita o intercâmbio. Mas pode ser arruinada por problemas de transporte.

Estes vetores não são isolados; as características de uns refletem-se nas potencialidades ou fraquezas dos outros. Mesmo que a integração seja principalmente uma aproximação comercial, ela é ponderada por outros fatores, políticos e sociais, que aproximam os países. Independente do modelo de acumulação de capital que possa ser projetado seja através da inserção competitiva da região no rearranjo global do sistema capitalista, ou através da ampliação da acumulação pela integração da própria região, em um possível subsistema periférico sul-americano; a integração comercial da América do Sul, por si mesma, seria benéfica para as economias da região.

Mas, com base no atual quadro de laços comerciais, um avanço significativo na integração intra-regional só ocorrerá quando, e se, houver uma 
clara identificação e associação de esforços nos demais vetores de interesses envolvidos em uma integração, em particular no político-estratégico e no físico-logístico. 


\section{Referências Bibliográficas}

BENAVENTE, José Miguel. ¿Cuán dinámicas son las exportaciones intrarregionales latinoamericanas? CEPAL, División de Desarrollo Económico, Serie Macroeconomía del Desarrollo, n. 12, Santiago de Chile, enero 2002.

. Exportaciones de manufacturas de América Latina: ¿Desarme unilateral o integración regional? CEPAL, División de Desarrollo Económico, Serie Macroeconomía del Desarrollo, n. 3, Santiago de Chile, 2001.

BIELSCHOWSKY, Ricardo (Org.). Ribeiro, Vera (Trad). Cinqüenta anos de pensamento da CEPAL. Rio de Janeiro: Record, 2000.

BIELSCHOWSKY, Ricardo. Vigência de los aportes de Celso Furtado. Revista de la CEPAL, Santiago de Chile, n. 88, 2006.

BRAGA, Marcio Bobik. Integração econômica regional na América Latina: uma interpretação das contribuições da CEPAL. Cadernos PROLAM/USP, São Paulo, v. 1, 2002.

CEPAL. Clasificaciones estadísticas internacionales incorporadas en el banco de datos del comercio exterior de América Latina y el Caribe de la CEPAL (Revisión 2). Cuadernos Estadísticos de la CEPAL, Santiago, n. 30, 2004.

. Estudio económico de América Latina y el Caribe 2004-2005. Santiago de Chile, septiembre 2005.

CEPAL. Unidad de Comercio Internacional de la Sede Subregional de la CEPAL en México. Intensidad tecnológica del comercio de Centroamérica y la república dominicana, Distr. limitada LC/MEX/L.587, n. 24, diciembre 2003.

CEPAL CAN 2000. Un programa de cómputo para analizar la competitividad internacional de paises y regiones. Disponível em: http://www.eclac.cl/ Acesso em: 1 fevereiro 2006.

CORTADA, Antonio Martins Comércio e integração do Brasil na América do Sul: uma avaliação de alternativas às limitaçóes logisticas na região amazônica. 193p. 2007. Dissertação (Mestrado) - Programa de Pós-Graduação em Integração da América Latina da Universidade de São Paulo (PROLAM/ USP), 2007. 
DI FILIPPO, Armando. Integración regional latinoamericana, globalización y comerciosur-sur.PalestraenlaDécimaReunión delComitélntergubernamental para la Coordinación y el Seguimiento de la Cooperación Económica entre Países en Desarrollo, Grupo de los 77, 1998. Disponível em http://www. eclac.cl/publicaciones/. Acesso em: 1 fevereiro 2006.

. La visión centro-periferia hoy. Revista de la CEPAL, Santiago de Chile, Octubre 1998. Numero Extraordinario. Disponível em: http://www.eclac. cl/publicaciones/ Acesso em: 1 fevereiro 2006.

DIAS, Vivianne Ventura; LIMA, José Durán. Production sharing in Latin American trade: a research note. CEPAL, SERIE Comercio internacional, n. 22, International Trade and Integration Division. Santiago de Chile: diciembre 2001.

DORNBUSCH, Rudiger. Los costos y benefícios de la integración económica regional. Integración Latinoamericana, p. 13-26, jun. 2006.

ESCAITH, Hubert; PAUNOVIC, Igor. Regional integration in Latin America and dynamic gains from macroeconomic cooperation. CEPAL, División de Desarrollo Económico, Serie Macroeconomía del Desarrollo, Santiago de Chile, n. 24, mayo. 2003.

FFRENCH-DAVIS, Ricardo. El comercio intralatinoamericano y su base analitica para el nuevo decenio. Borrador para Discusión, 22 agosto 2001.

GUIMARÁES, Samuel Pinheiro. Desafios e dilemas dos grandes países periféricos: Brasil e Índia. Revista Brasileira de Politica Internacional, n. 1, v. 41, p. 108-131, 1998.

HOUNIE, Adela et al. La CEPAL y las nuevas teorías del crecimiento. Revista de la CEPAL, n. 68, agosto. 1999.

IANNI, Octavio. Globalização: novo paradigma das ciências sociais. Revista de Estudos Avançados, São Paulo, v. 8, n. 21, 1994.

KEOHANE, Robert; NYE, Joseph. Power and interdependence. Boston: Little Brown, 1977. 
KOUZMINE, Valentine. Exportaciones no tradicionales latinoamericanas. Un enfoque no tradicional. CEPAL, División de Comercio Internacional y Financiamiento para el Desarrollo CEPAL, Serie Comercio internacional, n. 7, Santiago de Chile, junio. 2000.

KRUGMAN, Paul; OBSTFELD, Maurice. Economia internacional: teoria e política. 6. ed. São Paulo: Makron Books, 2005.

KUWAYAMA, Mikio; LIMA, José E. Durán La calidad de la inserción, internacional de América Latina y el Caribe en el comercio mundial. CEPAL, División de Comercio Internacional e Integración, Serie Comercio Internacional, n. 26, Santiago de Chile, mayo. 2003.

LAFER, Celso. Brasil: dilemas e desafios da política externa. Revista Estudos Avançados, São Paulo, v. 14, n. 38, p. 260-267, 2000.

LIMA, José Elías Durán; VENTURA-DIAS, Vivianne. Comercio intrafirma: concepto alcance y magnitud. CEPAL, Serie Comercio Internacional, n. 44, División de Comercio Internacional e Integración, Santiago de Chile, diciembre 2003.

MACHADO, Luiz Toledo. A teoria da dependência na América Latina. Revista Estudos Avançados, São Paulo, v. 13, n. 35, 1999.

MALDONADO, Raul. Avance y vulnerabilidad de la integración económica de América Latina y el Caribe. CEPAL, División de Comercio Internacional e Integración, Comercio Internacional, n. 32, Santiago de Chile, agosto. 2003.

MALLON, Richard. Un nuevo centro y una nueva periferia. Revista de la CEPAL, Número Extraordinario, Cincuenta años, reflexiones sobre América Latina y el Caribe, oct. 1998. Disponível em: http://www.eclac.cl/publicaciones/. Acesso em: 1 fevereiro 2006.

MITRANY, David. The functional theory of politics. New York: St. Martin's Press, 1975.

MORGHENTAU, Hans J. Politics among nations. New York: Ed. AA Knopf, 1961. 
OCAMPO, José Antonio. CEPAL cincuenta años reflexiones sobre América Latina y el Caribe. Revista de la CEPAL, Numero Extraordinario, Santiago de Chile, oct. 1998.

Raúl Prebisch y la agenda del desarrollo en los albores del siglo XXI. Revista de la CEPAL, n. 75, dic. 2001.

OLIVEIRA, Francisco. O caráter de periferia especial. Folha de São Paulo, 25 março 2001.

PIVA, JorgeMario Martinez; CORTÉS, Enrique. Competitividad centroamericana. CEPAL, Unidad de Comercio Internacional, Serie Estudios y Perspectivas, Sede Subregional de la CEPAL en México, México, D. F., n. 21, jun. 2004.

PREBISCH, Raul O mercado comum latino-americano e o regime de pagamentos multilaterais. In: BIELSCHOWSKY, Ricardo (Org.). Ribeiro, Vera (Trad). Cinqüenta anos de pensamento da CEPAL. Rio de Janeiro: Record, 2000. p. 349-361.

RODRÍGUEZ, Octavio. Prebisch: Actualidad de sus ideas básicas. Revista de la CEPAL, n. 75, dic. 2001.

ROLLINAT, Robert. Analyses du développement et theories de la dépendance en Amérique Latine. L'actualité d'un débat. Cadernos PROLAM/USP, São Paulo, v. 1, n. 6, 2005, p. 97-118.

WALLERSTEIN, Immanuel. World systems analysis: theory and methodology. Beverly Hills: Ed Sage, 1992.

WALTZ, Kenneth. Theory of international politics. New York: Ed. McGraw-Hill, 1979. 